\title{
Consumer Protection Against Confusion in The Trademark Law
}

\author{
Aleksandra Nowak-Gruca, PhD \\ Department of Civil and Economic Law \\ Cracow University of Economics
}

\section{Doi: 10.19044/elp.v5no1a1 $\quad$ URL:http://dx.doi.org/10.19044/elp.v5no1a1}

\begin{abstract}
Information has contemporarily become a good with a major market importance, which is why we observe many efforts of the European legislator and the national legislators aimed at protecting the information. What is also of utmost importance is the protection of the communication channels, because all the information asymmetries cause disruption in an economically efficient allocation of goods. The nature of communication between the traders and consumers generates the risk of confusion. Due to the large number of interferences in this area there is required a skilful interference in its course, which can be made with the use of the effective legal instruments. For this reason, the article presents the problem, not analysed previously in broader terms, of consumer protection against confusion in the trademark law. The issue of consumer protection from the perspective of accuracy and adequate transparency of market information has already been the subject of analyses and studies, yet they were mostly undertaken from the perspective of unfair competition law. It should be noted, however, that consumer protection against disinformation can be manifested also on the grounds of trademark law within the protective right in relation to the trademark against the risk of the confusion of the recipients. The aim of this article is to present the issues related to this specific form of the protection of the consumer as the recipient of the goods covered by a specific sign, in the context of the model of the average consumer in the European law.
\end{abstract}

Keywords: Consumer, the model of the average consumer, trademark, the functions of the trademark, the risk of confusion among the recipients.

\section{Introduction}

The information society requires of its members a high level of functional literacy. Information has now become a good of major importance in the market, which is why we observe many efforts of the European 
legislator and the national legislators aimed at protecting the information. From a market perspective, it becomes extremely important to protect communication channels, because all the information asymmetries cause disruption in an economically efficient allocation of goods. The nature of communication between the traders and the consumers generates a risk of confusion. Due to the large number of interferences in this area there is needed skilful interference in its course, which can be made with the use of effective legal instruments. Consumer policy in the EU law has undergone a long evolution, and is currently an autonomous as well as politically and legally independent field. It is significant that the current EU consumer policy, in addition to protecting the health, safety and economic interests, supports the consumers' right to information. Consumer protection against being misled constitutes, next to the unfair competition and antitrust issues, an important instrument governing the exchange of information in a competitive market. The issue of consumer protection from the perspective of accuracy and adequate transparency of market information has already been the subject of analysis and studies, yet they were mostly undertaken from the perspective of unfair competition law. It should be noted, however, that consumer protection against disinformation can be exercised also on the grounds of trademark law in the form of trademark protection rights against the risk of misleading the public. The aim of this article is to present the issues related to this specific form of protecting the consumer as the recipient of the goods bearing a given trademark, in the context of the model of the average consumer in the European law. The consumer interests related to information obligations are also protected in a specific way by the regulations concerning the requirements of the trademarks themselves. The requirement to have a distinctive character (abstract and concrete) eliminates from the protection those trademarks which are not suitable for distinguishing homogeneous goods in trade, which is certainly not without significance for the interests of the recipients of the goods. However, due to the framework of this study, these issues have not been covered by the present analysis.

\section{Consumer model in the trademark law in the context of the European model of the average consumer \\ 1.1. Introductory comments}

The EU's vision of prosperity includes consumer protection and the relevant policies of producers and traders, forced thereby, which will increase the competitiveness of the EU products in the global economy. The need for consumer protection is a natural consequence of the pursued integration policy, which originally was focused on the realization of the four freedoms under the Treaty. A standard cost of the integration are the risks to the consumer (to his life, health, safety and economic interests). Ensuring the free 
movement of goods, services, labour, capital and entrepreneurship needs to counter such integration activities which harm the interests of consumers (Tischner, 2012, p. 92).

The perceived need to protect undistorted market communication and the consumer's interests in respect of information duties, utterly important for its course, have succeeded in developing a specific model of the consumer the recipient of market communications. The EU model of consumer protection evolved along with the progressive integration processes and development of the common market (Gnela, 2011, p. 56). This evolution in the perception of the importance of the consumer and the need to protect its interests can be clearly seen in the case law of the Court of Justice. What was of utmost importance for the protection of the consumers against misinformation was the adoption of the Directive 2005/29/EC on unfair commercial practices ${ }^{1}$. The inclusion in the Directive of the provision concerning the model of the average consumer was a kind of culmination of the efforts of the Court of Justice in order to establish a single European standard of the consumer (Tischner, 2006, p. 244). In turn, the implementation of the Directive into the Polish law has led to the introduction of a legal definition of the average consumer. The model of an average consumer has functioned for a long time already in the trademark law, hence its characteristics - even though a brief one - is essential for the subsequent analysis. It is also worth reflecting on the significance of this model for the trademark law in the context of the assessment of the risk of misleading the public from the perspective of protecting the interests of the consumers.

\subsection{Average consumer model in the context of the selected judgments of the Court of Justice}

A. Tischner rightly points out that the jurisprudence of the Court of Justice clearly shows how much the understanding of the term "average consumer" is conditioned by the totality of the EU consumer policy, and above all, by the EU economic policy (Tischner, 2012: p. 92). The need to protect consumers clearly evolves with the process of the European integration. The frames of this study impose certain restrictions, hence the analysis below will cover only the problem of the average consumer as the recipient of goods or services on account of the imposed trademark 2 .

1 Directive 2005/29/EC of the European Parliament and of the Council of 11 May 2005 concerning unfair commercial practices in business-to-consumer internal market and amending the Council Directive 84/450/EEC, Directive 97/7/EC, 98/27/EC and 2002/65/EC of the European Parliament and of the Council and the Regulation (EC) 2006/2004, Official Journal of the European Union series L 149/22 of 11 June 2005.

2 It should be noted that the Industrial Property Act (the Act of 30 June 2000, Journal of Laws of 2013, item 1410, as amended, hereinafter Industrial Property Act) uses the term "recipient" 
The literature indicates (Jasińska, 2010, p. 109) that a milestone in the jurisprudence of the Court was the ruling in Gut Spriendenheide3. The case concerned a marketing slogan placed on the packaging of eggs that read "Sixgrain - 10 fresh eggs", supplemented by the information that the eggs came from hens fed with six-grain feed. In fact, the feed given to the hens contained only $60 \%$ of grain components. In the cited case, the Court stated that the national court in determining whether a particular statement, used for promotion of the sale of eggs, misleads buyers, must take into account the expectations of an average consumer who is properly informed, reasonably observant and circumspect. However, it is not prohibited that the national court, having difficulties with the assessment of the occurrence of an error, referred, in accordance with the principles arising from the national law, to surveying the consumers or to an expert opinion as a tool to support the assessment of the case. In spite of the fact that this particular case concerned the advertising, the Court's considerations were related to the concept of the average consumer not only from the point of view of fair competition and consumers' rights, but also from the perspective of the trademarks law and other symbols (see paragraph 32 of the merits of reason of the cited judgment).

By accepting the above mentioned restrictions on the frames of the study, we can assume that there is a certain perpetuated approach in the trademark law, according to which the average consumer of a specific type of goods is seen as a well-informed, duly careful and cautious person, whereas the level of perception of the average consumer may vary depending on the type of goods or services. In addition, it is now accepted that the linguistic, cultural and social differences may cause that a trademark which does not mislead the consumers in one country, can have this very effect in another country ${ }^{4}$.

The above mentioned features of the average consumer have now become the part of the model provided for in the Directive 2005/29/EC,

(see art. 296 paragraph 2 point 2 and art. $132^{1}$ point 3 and 5). It is obvious that the recipients of goods or services that bear the trademark may also be professional actors, yet the Court of Justice in a number of its rulings on the issue of trademarks referred directly to the model of the average consumer. See K. Jasińska 2010, p. 100, footnote 7, and the judgments cited therein.

3 Case C-201/96 Gut Springenheide, judgment of 16 July 1998, Collected Rulings 1998, p. I4657.

4 Case C-220/98 Estee Lauder, judgment of 13 January 2000; Case C-313-94 Graffione, judgment of 26 November 1996; see also: G. Dinwoodie, D.S. Gangee 2014 [access 24 September 2016]. The authors presented the thesis that the model of the consumer applied in this area of law is partly empirical and partly normative, indicating when the examined consumer behaviour is taken into consideration. In their opinion, the Court of Justice supports the use of the empirical evidence, which results in a more diversified protection, taking into account the characteristics of a given market and language differences. 
adopted in the Polish law in art. 2 point 8 of the Act of combating unfair commercial practices5. It is worth noting that the Guidance on the Implementation/Application of Directive 2005/29/EC on Unfair Commercial Practices6 allows the analogous application under the Directive of the case law of the Court of Justice and the General Court (formerly the Court of First Instance) generated by the assessment of a confusing trademark. It is of utmost importance for the considerations presented here that the average consumer normally perceives a trademark as a whole and does not analyse its various components. In addition, the average consumer only rarely has the opportunity to directly compare the opposing symbols, therefore in their perception, the consumer is based on the imperfect image left by the symbols in his memory.

\subsection{The average consumer in the Directive 2005/29/EC. An outline of the issues}

The text of the Directive 2005/29/EC contains no definition of the term "average consumer". The Directive uses this concept in the definition of unfair market practices (art. 5 paragraph 2 point b and art. 5 paragraph 3), in the definitions of misleading practices by action(art. 6 paragraph 1 and 2) and by omission (art. 7 paragraph 1 and 2) as well as in the definition of aggressive marketing practices. Extensive explanations on this concept are provided in points $18^{8}$ and $19^{9}$ of the preamble of the Directive. It is important that the Directive adopts the average consumer model developed in the case law of the Court of Justice. To use some simplifications, for the purposes of this study, we can conclude that the benchmark consumer, according to the regulation of the Directive, is a well-informed, reasonably attentive and cautious recipient, while the application of this concept in the scope of the undertaken evaluations cannot be detached from the social, cultural and linguistic factors. Where a

5 The term "average consumer" has been introduced to the definitions section of the Act on combating unfair commercial practices (the Act of 23 August 2007, Journal of Laws of 2015, item 1348, hereinafter referred to as the Act on combating unfair commercial practices). According to art. 2 section 8 , the concept of the average consumer shall be understood as the consumer who is reasonably well informed, observant and circumspect; the assessment is carried out taking into account social, cultural and linguistic factors, as well as the membership of a consumer to a particular group of consumers, which shall be understood as a clearly identifiable group of consumers, particularly vulnerable to the impact of market practice or to the product which the market practice concerns, because of the particular characteristics such as age, physical or mental disability. Unfortunately, the above legislative tool of the Polish legislator was not entirely successful from the perspective of the objectives of the Directive 2005/29/EC, see more broadly A. Michalak 2008, p. 56; A. Tischner 2012, p. 101, K. Jasińska 2010, p. 117.

6Commission Staff Working Document - Guidance on the Implementation/Application of Directive 2005/29/EC on Unfair Commercial Practices, document SEC (2009) 1666 of 3 December 2009. 
certain commercial practice is designated for a particular group of consumers, particularly vulnerable to unfair market practices, its impact should be assessed from the perspective of the average member of this group. In certain specific cases, it is possible, and even advisable, to make assessments from the point of view of an entity other than the average consumer. It is in fact approved to assess commercial practices also from the point of view of the people who, according to the trader's intention, were not intended to be the sole recipients of a certain practice, but in fact found themselves in the scope of its influence. One may not have too high expectations in respect of the benchmark consumer protected by the Directive 2005/29/EC as to its independence in obtaining the information necessary to make a rational decision on the market. This concept should be interpreted in compliance with art. 114 of TFEU, which provides for a high level of consumer protection.

It seems that the so-called average consumer test, proposed in the Directive, coincides with the approach settled for the assessments undertaken under the trademark law. Consistency of the assessments in this regard certainly promotes confidence and the practice of law ${ }^{7}$.

\section{The functions of the trademark and the interests of the consumer}

\subsection{The consumer's right to information. Introductory comments}

The tool for the communication between the traders and the consumers on the market is a widely understood "commercial communication", and wherever a flow of information takes place, there is a risk of confusion. The competition law is dominated by the principle of truth, and from the latter there directly follows the fundamental right of the consumers to information. This right is made concrete in the form of specific obligations on the part of the traders to provide information and the traders' responsibilities to prevent consumers being confused (Tischner, 2006, p. 203).

Free consumer decisions are an extremely important element of the undistorted market interactions and all measures introducing consumer confusion are a violation of the right to information. Reliable information is one of the basic mechanisms that regulate the exchange in the market, and any disruption in this area results in inefficient allocation of scarce resources, and as undesirable market phenomena, should be eliminated.

Intensive development of visual arts in the use of human perceptual abilities, also for persuasion, provides the traders with completely new tools of influencing the recipients. The trademark becomes extremely important market message with specific opportunities to influence the decision-making process of the consumer. At this point the question arises whether the dynamic

7 In this context, there must be presented a negative assessment of the implementation of the Directive into the Polish law, see more broadly A. Tischner 2012, p. 126. 
development of visual communication does not pose new threats for the consumer and whether these could not somehow be eliminated within the framework of the trademark law. For this purpose it is necessary to look, at least briefly, at the currently protected features of the trademark in the context of protecting the interests of the consumers.

\subsection{The functions of the trademark}

The development of the legal institution of the trademark is directed toward the relationship between the mark and the goods (services), which are used to distinguish homogeneous goods (services) in trade (WojcieszkoGluszko, 2017, p. 473). In economics, the trademark operates as a brand (Kotler, 1994, p. 410). The trademark in the ontological aspect is a unitary relation ofthe mark and the goods, reflected in human consciousness, including general ideas about a given commodity, differentiated on the basis of its origin (Skubisz, 1988).

Trademarks belong to intangible goods, which are not intellectual in nature, yet they represent a carrier of information about the commercial origin of the goods or services. The essence and the significance of the trademark appears only in connection with the goods, the business and broadly understood economic activity ${ }^{8}$.

A trademark is most frequently described in regard to the function which it plays in the economic reality. The functions of the trademark shall mean the overall impact of the trademark on the market [R. Skubisz 2001, p. 163].

The doctrine and the case law traditionally distinguish the following functions of the trademark: marking the origin, quality function and advertising function. The latest views of the doctrine, formed on the basis of the case law of the Court of Justice, also mention other functions, in particular, investment and communicative one ${ }^{9}$. It is also indicated that the other functions are derived in their nature from the three above-mentioned ones (Skubisz, 2012, p. 94).

Traditionally, the primary importance is given to the function of origin labelling. It involves providing the information to a potential buyer that all the

\footnotetext{
8 In light of the Industrial Property Act, the trademark can be any sign (symbol) capable of being represented graphically, if such a sign is capable of distinguishing the goods of one undertaking from those of other undertakings. Trademark may in particular be an expression, a drawing, ornament, colour composition, spatial form, including the form of goods or their packaging, as well as melodies or other acoustic signals (art. 120 of the Industrial Property Act).

9 See the most frequently cited: the judgment of 18 June 2009, Case C-487/07, L'Oreal, Collected Rulings 2009, p. I-5185, paragraph 60; the judgment of 23 March 2010 in Joined Cases C-236/08 to C-238/08 Google France and Google, Collected Rulings 2010, pp. I-2417.
} 
goods bearing a certaintrademark come from the same source (the identity of the origin of the goods). It is emphasized that a potential buyer, usually the consumer, can expect that all the goods which a given trademark is intended to mark are derived from the trademark proprietor or from the entities under his control.

The Court of Justice defines the basic function of the trademark as a guarantee to the consumer (or other end-user of the product) of the identity of the origin of the goods bearing a certain trademark, by enabling him, without any danger of confusion, to distinguish those goods or services from the goods or services of another origin. In this role, the mark is a guarantee that all the marked goods or services have been manufactured or supplied under the control of a single undertaking which is responsible for their quality (Żelechowski, 2015, p. 4 and the CJEU rulings cited there).

Moreover, the attention in the doctrine is drawn to the fact that currently the criterion of the commercial origin of the goods should be understood more widely, i.e. in the context of the very ability of the trademark to distinguish the goods from other goods. The changes in the practice of selecting and using the trademarks caused a shift of emphasis from the position of origin labelling to the direction of the guarantee of the commercial identity of the origin of goods (Skubisz, 2001, p. 167).

The quality function comes down to induce in the recipients the belief that all goods have the same, consistent quality, because they have the same origin. It is pointed out that the trademark can fulfil this function only when as a result of the prior use of the trademark the recipients developed the idea that the goods bearing a certain trademark are characterized by a specific, consistent quality. In order for the trademark to fulfil this function it will be therefore essential to create positive experience in the purchasers of goods or services bearing thistrademark, resulting in the specific expectations as to the consistent quality of the products under that trademark. This feature is sometimes referred to as a guarantee function or the function of the protection of the trust of the purchasers of goods (Skubisz, 2001, p. 170).

The trademark also serves as advertising. This function is described as the ability of the trademark to attract the attention of a potential buyer of the goods and to trigger in him the need to purchase a particular product because of the trademark associated with it. This advertising function is characteristic of only those trademarks where the goods which they represent enjoy a good reputation among customers (so called good will). It is interesting to note here the special role of reputable trademarks, which, when detached from the goods, are themselves the carriers of good will and all sorts of associations and perceptions of the consumer. This function is an expression of the attractive force of the trademark that attracts the customer to the product. Similarly to the quality function, the advertising function does not arise from 
the very essence of the trademark and its role fulfilled by a specific trademark is a result of the adoption by the trademark proprietor of specific actions and efforts.

The case law of the Court of Justice clearly indicated the further functions of the trademark - investment and communication functions, whereas the catalogue of the functions in the light of the Court's position remains open (Żelechowski, 2015, p. 6).

The investment function, indicated by the Court of Justice, frequently overlaps with the function of advertising. The so-called "investment" function is associated with the use of the trademark in order to gain or retain a reputation likely to attract or bind to it the consumers, and unlike in case of the advertising function, gaining or retaining the reputation takes place not only as a result of advertising, but when using other commercial techniques ${ }^{10}$.

In the case of the communication function, the Court of Justice did not so far explain precisely how to understand this function and how there should be formed its scope of protection. In the statements made so far, the Court of Justice indicates, among other things, that "[...] trademark can provide consumers with various kinds of information on the product on which it was placed. It can involve information resulting directly from the sign forming a part of the trademark (for example, information on the material qualities of the goods resulting from the possible descriptive elements contained in a complex trademark) or, more frequently, the information "collected" around the trademark as a result of the promotional or advertising activity carried out by the proprietor - for example, the information relating to non-material features which create the overall image of the product or the business (e.g. quality, reliability, etc.) or its detailed image (e.g. a certain style, luxury, power)" ${ }^{11}$. This information property of the trademark deserves protection according to the Court of Justice.

\subsection{Specific importance of the protection of the communicative function of the trademark}

The doctrine describes the communicative function of the trademark as the overall capacity of the trademark to invoke specific ideas of the goods among the customers. It combines in itself the abovementioned functions (i.e. about the source of origin of the goods, the quality of the goods, the attractiveness of the trademark) (Żelechowski, 2015, p. 6). The communicative function is considered to be superior over other functions

10 See the judgement of the Court of Justice of 22 September 2011 in the case C-323/09, Interflora and Interflora British Unit, EU:C:2011:604, Collection of Rulings 2011, p. I-8625, points 60-64.

11 See the judgment of 18 June 2009 in the case C - 487/07 L'Oréal et. al., Collection of Rulings, p. I-5185, point 67. 
(Bailey, 2013). In addition, it is indicated in the literature that today there can be seen the attempts to replace the traditional approach to the functions with a new approach, referred to sometimes as the science of protecting the communicative function of the trademark, which grew on the basis of interdisciplinary research. It is pointed out that the combination of research in economics, marketing and psychology led to the perception of the communicative function as a certain market phenomenon. The trademark is regarded as information channel between the vendor and the purchaser of the goods or as the tool of market communication (Tischner, 2008, p. 31).

It should be noted that in today's economy, consumers' behaviour differs significantly from the approach to them as settled in the science of law and economics. Consumer behaviour is influenced by the multiplying channels of communication and specialized marketing techniques related to them that significantly shape the attitudes of consumers also in relation to the trademark (Rea, 2012).

It is worth repeating that on the basis of the theory of the functions of the trademark, in the light of a new approach to the protection of the trademark formed on the background of the case law of the EU Court of Justice, the trademark is increasingly more often perceived as the image of the product. Thus, the distribution of the weight of protection in the light of the need to protect the interests of the consumers should aim to protect the bond that is formed on the basis of the relations with the trademark. These bonds are based on trust, and the benefits of them rely primarily on reducing the risk of the transaction by minimizing the risk of purchase, simplifying the selection process, saving time. Trademark equips the consumer with the information and considerably simplifies the decision-making process related to the purchase of goods / services, while expanding the possibilities to reduce the excess information. From this perspective there arises as crucial the need to protect the consumer's right to act in transparent market conditions. Therefore, in determining the scope of the protection of the trademark there cannot be left aside, and there can be even postulated the value associated with a communicative function of the trademark (Beier, 1970, p. 61-62). The trademark should be the guarantor of the proper information, so that it is not confusing. Full control over the course of marketing communication lies not only in the interest of the proprietor of the trademark, but also in the interest of the consumer.

\section{Protection of the consumer against being confused under the trademark law}

\subsection{Introductory remarks}

As noted by A. Tischner, a confusing market communication violates the consumer's right to economic self-determination, invoking in him the 
wrong idea about the characteristics and the quality of the purchased goods. Therefore, an adequate instrument to protect the consumer in such cases is the prohibition of confusion. The universality of market practices based on confusion causes that combating these practices should take individualized forms, independent of individual protection against actual disinformation of the individual. The issue of confusion is the keystone of several disciplines of law: the law on unfair competition, industrial property law and consumer protection law. The term "confusion"is a vague concept which needs to be made more specific in judicial decisions. This construction opens up the legal system for the evaluation undertaken outside the system (Tischner, 2006, p. 203-206, Węgrzyn, 2013, p. 89 -91).

In cases of violation of the protection right of a trademark, the court is obliged to take into account all relevant factors, which are important for assessing the risk of confusion ${ }^{12}$. Therefore, the subject of further consideration will be the methodology of assessing the likelihood of confusion, a brief one - due to the form of the study - carried out under the terms of the analysis of the abovementioned factors from the perspective of the protection of the consumer rights to information (self-determination).

\subsection{The criteria for assessing the likelihood of confusion}

A likelihood of confusion is the fundamental institution of the trademark law. It consists, in general terms, in the possibility of erroneously assigning, contrary to reality, the origin of the goods by the recipient, due to the trademark, to the person authorized for the registration of the trademark (Szczepanowska-Kozłowska, 2007, p. 4). There can be differentiated the direct and indirect risks of confusion. The direct risk of confusion includes the possibility of mistakes on the part of the consumers that the goods (services) of a third party bearing the same or a similar trademark originate under the undertaking of the proprietor of the trademark. In turn, the indirect risk of confusion includes confusion as to economic, legal or organizational bonds between the undertaking of the third party and the proprietor of the trademark. This risk, therefore, includes the possibility of confusion as to the relations between the undertaking of the third party and the proprietor of the trademark. Both in the EU law and in the Polish law every form of risk of confusion is an obstacle to register the trademark with later priority, and if registered - it constitutes the basis for the cancellation of the protective right granted. Each form of such a danger is the constitutive condition of violating the protective right of the trademark.

12 See Case C - 251/95 SABEL, the ECJ judgment of 11 November 1997, Collection of Rulings 1997, p. I-6191, cited by R. Skubisz 2012, p. 1113, comments to footnote 248. 
The assessment of confusion due to an earlier trademark requires prior determinations in respect of:

a) the identity or similarity of the goods (services) and the degree of such similarity,

b) the identity or similarity of the trademarks in conflict and the degree of such similarity,

c) the degree of the recognisability of the earlier trademark (the degree of a certain distinctive character of this trademark) and, optionally,

d) other criteria that are important for assessing the risk of confusion (e.g. the earlier trademark being the part of the series of trademarks).

Only after the verification of all these factors (criteria) of the risk of confusion, there must be undertaken a comprehensive risk assessment. This assessment is to determine whether from the point of view of the average recipient of a particular type of goods (services) there is a risk of confusion as to the origin of goods (services), due to the earlier trademark (the earlier trademarks) (Skubisz, 2012).

Reference point for assessing the risk of confusion as to the origin of goods and services is a person of the average customer (consumer). As was presented in the considerations above, the latter is a person who is well informed, duly attentive and careful.

In conclusion, it can be stated that, in accordance with the approach settled in the jurisprudence, mainly due to the judgments of the Court of Justice, the likelihood of confusion arises when the average consumer may mistakenly think that the goods or services bearing the trademark originate from the undertaking of the proprietor of the trademark or from the undertakings of the entities remaining with it in economic or organization relations. At the same time, this assessment, unlike on the basis of unfair competition law, should apply only to those circumstances that are related to the application of the trademark.

\subsection{The overall assessment of the likelihood of confusion and the interests of the consumers}

The likelihood of confusion implies the simultaneous existence of the identity or similarity between the trademark applying for the registration and an earlier trademark as well as the identity or similarity between the goods and services for which the registration is made, and those for which the earlier trademark has been already registered. These conditions must be met cumulatively $^{13}$. In other words, in all cases in which there arises the problem of the similarity of the opposing trademarks, it is the result of two closely

13 In this way, among others, the ECJ judgment of 12 October 2004 in the Case C-106/03, P, Vedial vs. OHIM, Rec. p. I-9573, point 51. 
related elements: firstly - the similarity of the signs, and secondly - the similarity (homogeneity) of the goods / services for which the trademarks are applied, registered or used. Both of these factors determine the scope of the trademark protection.

As mentioned above, the assessment of the risk of confusion must be holistic, taking into account all relevant elements of the state of facts. The question whether or not there arises the risk of confusion in a particular case, depends on the overall evaluation of several interdependent criteria, such as the similarity of the goods and services; similarity of the signs; the relevant circle of recipients; the presence of the distinctive and dominant elements in the conflicting signs; the degree of recognition of the earlier trademark; other factors. In the course of the assessment of the likelihood of confusion there must be in the first place determined the abovementioned factors and then it is necessary to determine their significance in the individual case.

The relevant circle of recipients consists of the actual or the potential purchasers of the goods bearing the trademarks, namely of the consumers who buy goods or services or may purchase them in the future. Determination of the relevant circle of recipients consists, therefore, in identifying the recipients of goods or services bearing the trademark and should be made with regard to their nature.

The next step after determining the relevant group of recipients should be the identification of who are the standard purchasers of the specific goods or services, namely the average recipients. As already indicated, the benchmark of the average recipient, adopted by the European courts, has a unitary character throughout the European Union. It is generally accepted that the average consumer of certain product category is a person who is properly informed, reasonably observant and reasonable. The adoption of such a definition means that the average consumer is a person with specific knowledge about the world, having the ability to absorb information, but it acquires it with a certain amount of criticism because of the awareness of the commercial role of the trademark. The assessment of the likelihood of confusion is made, therefore, always from the point of view of the average consumer, i.e. a well-informed person, sufficiently careful and rational, who belongs to the relevant group of recipients of certain goods or services.

In a situation where the average consumer will not be able in any way to presume the origin of the goods from the same undertaking, the risk of confusion will not take place. The perception of the trademarks by the average consumer is therefore crucial in assessing the risk of confusion and depends on the nature of those goods and services.

The above outlined approach to the assessment of a likelihood of confusion of the recipients as a consequence of the application of the identical or similar signs for the identical or similar products aimed to draw attention to the 
interests of the consumers, which can be protected within the framework of the trademark law. As can be clearly seen, the model of an average customer (consumer) is the central point of reference for the above evaluations. As mentioned above, the rapid development of human sciences results in using their outcome by the entrepreneurs in attracting the attention of customers and actively influencing their purchasing decisions. The use of the achievements of neuroscience in advertising and marketing, coupled with the rapid development of visual techniques, presents the law with completely new challenges.

For the modern consumer, burdened with too much information, the protection of the identity of the source of origin of the goods, referred to in this article, is undoubtedly of great value. It is especially the case because the said protection of consumer interests takes place in a way collaterally, somehow in the context of the rivalry between the entrepreneurs for the exclusive use of a particular sign, free from the risk of confusion. The approach to the determination of the likelihood of confusion, settled in the doctrine and jurisprudence, whose central point is the recipient of the goods, is not without significance for the interests of consumers. The trademark, especially a highly distinctive one, still remains an important tool for market communication, and although the above thesis is not accurate in every case (e.g. in the case of the so-called "impulse goods"), the sign that is contemporarily the image of the goods, still remains an important instrument for controlling the decisions of consumers. For this reason, it is important to provide the consumers with the maximum free choice, and the latter can take place only in the conditions of the most extensive, the fullest and most adequate information. The confusion as to the identity of the origin of the goods or services undoubtedly seriously disrupts the market exchange, therefore any legal instruments that aim at minimizing the risk of confusion, deserve appreciation and consideration, which was the purpose of this article.

\section{Conclusions}

The EU's vision of prosperity includes consumer protection as well as the relevant policies of producers and traders forced thereby, which will increase the competitiveness of EU products in the global economy. The need for consumer protection is a natural consequence of the policy of integration.

The issue of confusion is of interest to several disciplines of law: the law on unfair competition, industrial property law and consumer protection law. The term "confusion" is a vague concept, which requires specification in judicial decisions. It should be emphasized that the risk of confusing the recipients is a basic institution of the trademark law. It consists, in general terms, in the possibility of erroneously assigning the origin of the goods by the recipient, in a manner contrary to the state of facts, due to the trademark, to the proprietor 
of the trademark. The risk therefore includes the possibility of confusion as to the ties between the undertaking of the third party with the proprietor of the trademark. Both in the EU law and in the Polish law every form of risk of confusion is an obstacle to register the trademark with a later priority, and in case of its registration - it constitutes the basis for the cancellation of the right of protection. Each form of this risk is also a constitutive condition for infringement of a protective right granted in respect of the trademark.

Under the trademark law the protection of the interests of consumers is made in a way collaterally, in the context of rivalry between the traders of the exclusive use of a particular sign, free from the risk of confusion. The approach to the determination of the likelihood of confusion, as settled in the doctrine and jurisprudence, whose central point is the recipient of the goods, is not without significance for the interests of consumers and should be also paid attention to in this context. It is especially the case in light of the new approach to the protection of the trademark formed in the context of the case law of the Court of Justice of the EU, according to which the trademark is increasingly often perceived as the image of the product. Thus, the weight of the burden of protection in the light of the need to protect the interests of consumers should aim to protect the bond that is formed on the basis of relations with the trademark. These ties are based on trust, and the benefits of them rely primarily on reducing the transactional risk by minimizing the risk of purchase, simplifying the selection process, by process of saving time. The trademark equips the consumer with information and considerably simplifies the decision-making process related to the purchase of goods / services, and should therefore be the guarantor of the proper and non-misleading information. Full control over the course of market communication lies not only in the interest of the proprietor of the trademark, but also in the interest of the consumer.

\section{References}

Ametrano, F.M [2014] "Hayek Money: The Cryptocurrency Price Stability Solution", http://papers.ssrn.com/sol3/papers.cfm?abstract_id=2425270;

Bank of England (2014 Q3), Ali R., of the Bank' S Financial Market Directorate Infrastructure, Barrdear J., of the Bank' S Monetary Assessment and Strategy Division, and Clews R. and Southgate J., of the Bank' S Markets Directorate, "Innovations in payment technologies and the emergence of digital currencies";

Davidson, L., W.E. Block [2015], "Bitcoin, the Theorem Regression, and the Emergence of has New Medium of Exchange", the Quarterly Newspaper of Austrian Economics, vol. 18, n 3, pp. 311-338 
Decker, C, Wattenhofer, R. Information propagation in the bitcoin network. In: Proocedings of the International IEEE Conference one Peer-to-Peer Computing (P2P). 2013;

Dominic Frisby, "The Incredible Technology behind Bitcoin Is about to Change the World" [files], Insider Business, January 21st, 2015;

Dupre, D., J. - F. Ponsot J. - M. Servet [2015], the bitcoin against the revolution of the commun runs, communication to the 5th congress of the French Association of political economy, Lyon, July; HEEKS R., "Understanding "Gold Farming" and Real-Money Trading ace the Intersection of Real and Virtual Economies", Newspaper of Virtual Worlds Research, Vol.2 n4, February 2010;

Herlin P. (2013), "the revolution in the currencies: to circumvent the banks and the States", in the Revolution of Bitcoin and the complementary currencies: A solution to escape from the banking system and the euro, Eyrolles Editions and Atlantis, 2013, pp. 32-40;

Kibum Kim, Consultant At KPMG, Seoul, Korea, Taewon Kang, Ph.D Candidate At Seoul University National, Seoul, Korea Does Technology Against Corruption Always Lead to Benefit? The Potential Risks and Challenges of the Blockchain Technology, 2017, pages 12 and 15;

Maftei, L. (2014), BitCoin - between legal and informal, THESE Working Papers, Vol.6, No.3, pp. 53-59;

THANKACHEN J., "Deep Web: Proverbial the Safe House for Cybercriminals", Wired, August 22nd;

The 'Great Bitcoin Exodus' has totally changed New York' S bitcoin ecosystem, New York Business Newspaper by Michael Del Castillo, the $8 / 12 / 2015$. 